\title{
Diurnal Operation of the Xanthophyll Cycle and the Antioxidant System in Apple Peel
}

\author{
Lailiang Cheng1 and Fengwang $\mathrm{Ma}^{2}$ \\ Department of Horticulture, Cornell University, Ithaca, NY 14853
}

\begin{abstract}
AdDitional INDEX wORDS. Ascorbate peroxidase, catalase, dehydroascorbate reductase, glutathione reductase, Malus $\times$ domestica, monodehydroascorbate reductase, photosystem II efficiency, superoxide dismutase, thermal dissipation

ABstract. Xanthophyll cycle conversion and the antioxidant system in the peel of apple fruit (Malus $\times$ domestica Borkh. 'Liberty') were monitored in the field over a diurnal course at about 3 months after full bloom. Compared with leaves, sun-exposed peel of apple fruit had much lower photosystem II operating efficiency at any given photon flux density (PFD) and a larger xanthophyll cycle pool size on a chlorophyll basis. Zeaxanthin (Z) level increased with rising PFD in the morning, reached the highest level during midday, and then decreased with falling PFD for the rest of the day. At noon, $Z$ accounted for $>90 \%$ of the xanthophyll cycle pool in the fruit peel compared with only $53 \%$ in leaves. Efficiency of excitation transfer to PSII reaction centers $\left(F_{\mathrm{v}}{ }^{\prime} / F_{\mathrm{m}}{ }^{\prime}\right)$ was negatively related to the level of $\mathrm{Z}$ in fruit peel and leaves throughout the day. In fruit peel, the antioxidant enzymes in the ascorbate-glutathione cycle, ascorbate peroxidase (APX), monodehydroascorbate reductase (MDAR), dehydroascorbate reductase (DHAR) and glutathione reductase (GR) showed a diurnal pattern similar to that of incident PFD. In contrast, the activities of APX and GR in leaves did not change significantly during the day although activities of both MDAR and DHAR were higher in the afternoon than in the morning. In both fruit peel and leaves, superoxide dismutase activity did not change significantly during the day; catalase activity showed a diurnal pattern opposite to that of PFD with much lower activity in fruit peel than in leaves. The total ascorbate pool was much smaller in fruit peel than in leaves on an area basis, but the ratio of reduced ascorbate to oxidized ascorbate reached a maximum in the early afternoon in both fruit peel and leaves. The total glutathione pool, reduced glutathione and the ratio of reduced glutathione to oxidized glutathione in both fruit peel and leaves also peaked in the early afternoon. We conclude that the antioxidant system as well as the xanthophyll cycle responds to changing PFD over the course of a day to protect fruit peel from photooxidative damage.
\end{abstract}

Although green leaves are the main organ performing photosynthesis in plants, fruit is also able to photosynthesize. Compared with leaves, however, fruit has a much lower photosynthetic capacity (For review, see Blanke and Lenz, 1989). Well-exposed fruit experiences an extremely wide range of photon flux density (PFD) on a daily basis just like leaves do. In the absence of other environmental stresses, the PFD levels early in the morning and late in the afternoon often limit leaf photosynthesis, but leaf photosynthesis can only use up to 50 to $60 \%$ of the absorbed PFD at midday under full sun (Cheng, 2003; Demmig-Adams et al., 1996). Considering that fruit has a very limited capacity for utilizing PFD in photosynthesis, it is expected that more excess absorbed PFD exists in the peel of fruit than leaves at midday. In addition, because fruit has a much lower transpiration rate due to lower stomatal density and larger diffusive resistance, fruit peel temperature is much higher than leaves under light (Glenn et al., 2002).

Excess absorbed PFD can be dissipated as heat in the antenna pigment complex of photosystem II (PSII) (Demmig-Adams and Adams, 1992; Müller et al., 2001). This involves a pH difference across the thylakoid membrane and a xanthophyll cycle. As PFD increases, the acidification of thylakoid lumen activates violaxanthin (V) de-epoxidase, which converts $\mathrm{V}$ to zeaxanthin (Z) via antheraxanthin (A) (Hager, 1969; Hager and Holocher, 1994). Low lumen $\mathrm{pH}$ also results in protonation of proteins in

Received for publication 15 Oct. 2003. Accepted for publication 11 Jan. 2004. This work was supported in part by Washington Tree Fruit Research Commission. The authors wish to thank Lisong Chen, Chris Watkins, and Sunita Kochhar for helpful discussions on antioxidant measurements and Rich Raba for technical assistance with HPLC.

'Corresponding author; e-mail LC89@Cornell.edu.

${ }^{2}$ Current address: Department of Horticulture, Northwest Sci-Tech University of Agriculture and Forestry, Yangling, Shaanxi 712100, P.R. China. the PSII light-harvesting complexes. The interaction of $\mathrm{Z}$ and/or A with the specific sites of the protonated PSII proteins induces a conformational change that leads to increased quenching of excitation energy (Gilmore, 1997; Müller et al., 2001). When PFD decreases, epoxidation of $Z$ and $A$ to $V$ occurs to ensure efficient light harvesting. Xanthophyll cycle operates dynamically in leaves in response to changing PFD during the day (Adams and DemmigAdams, 1992). This process enables potentially destructive excess PFD to be harmlessly dissipated as heat, thereby protecting PSII reaction centers from photo-oxidative damage (Demmig-Adams and Adams, 1996; Demmig-Adams et al., 1997).

Photoreduction of oxygen and the subsequent detoxification of reactive oxygen species is another photoprotective mechanism plants use to cope with high PFD (Asada, 1999). The detoxification of the reactive oxygen species is undertaken by an integrated system of enzymatic and nonenzymatic antioxidants. The superoxide anion, the initial product of photoreduction of $\mathrm{O}_{2}$, is dismuted by superoxide dismutase (EC 1.15.1.1, SOD) to $\mathrm{H}_{2} \mathrm{O}_{2}$ and $\mathrm{O}_{2} \cdot \mathrm{H}_{2} \mathrm{O}_{2}$ is converted to $\mathrm{H}_{2} \mathrm{O}$ by catalase (EC 1.11.1.6, CAT) in peroxisomes (Willekens et al., 1995), or via the ascorbate-glutathione cycle in chloroplasts and the cytosol (Noctor and Foyer, 1998). The ascorbate-glutathione pathway involves ascorbate peroxidase (EC 1.11.1.11, APX), monodehydroascorbate reductase (EC 1.6.5.4, MDAR), dehydroascorbate reductase (EC 1.8.5.1, DHAR), glutathione reductase (EC 1.6.4.2, GR), ascorbate (AsA), glutathione (GSH), and $\mathrm{NAD}(\mathrm{P}) \mathrm{H}$ in a series of cyclic reactions to detoxify $\mathrm{H}_{2} \mathrm{O}_{2}$ and also regenerate AsA and GSH (Noctor and Foyer, 1998). The diurnal regulation of the antioxidant system relative to incident PFD is unclear. It appears that the diurnal change of antioxidant enzymes in leaves depends on each individual enzymes and plant species. Activities of SOD and APX in cork oak (Quercus suber) leaves did not vary between predawn and midday; activities of MDAR, DHAR, and GR were 
higher at midday than at predawn; CAT activity was lower at midday than at predawn (Faria et al., 1996). The activities of SOD, APX, and GR and the content of AsA and GSH in rice leaves at 60 days after transplanting increased in the morning and reached a maximum at midday (Yang et al., 2001).

To date, leaves have been the primary focus of understanding the photoprotective mechanisms in plants with very little information on fruit. Yet, fruit is an integral part and the final harvestable organ of many horticultural crops. Elucidating the photoprotective mechanisms that operate in the peel of fruit is important for their potential application in horticultural manipulations to minimize high light-induced damage, such as sunburn of apple. Considering the limited capacity for utilizing absorbed PFD in photosynthesis of fruit, it is possible that the antioxidant system, as well as xanthophyll cycle-dependent thermal dissipation, in fruit peel is regulated diurnally in response to changing incident PFD. The objectives of this study were to determine the diurnal operation of both xanthophyll cycle and the antioxidant system in the peel of sun-exposed apple fruit.

\section{Materials and Methods}

Plant materials And Sampling. Nine-year-old apple (Malus $\times$ domestica Borkh. 'Liberty') trees on M.9 rootstock were grown at a spacing of $1.52 \times 4.27 \mathrm{~m}$ in the field at Cornell Orchards in Ithaca, NY $\left(42^{\circ} 26^{\prime} \mathrm{N}, 76^{\circ} 29^{\prime} \mathrm{W}\right)$. The trees received standard horticultural practices and disease and pest control. On 10 Aug. 2002, $\approx 3$ months after full bloom, fruit and leaves that were fully exposed to sunlight on the south part of the canopy were chosen to measure chlorophyll fluorescence starting from predawn and then every 2 to $2.5 \mathrm{~h}$ throughout the day. After measuring fluorescence, leaf discs $\left(1 \mathrm{~cm}^{2}\right.$ in size $)$ and fruit peel discs $\left(1 \mathrm{~cm}^{2}\right.$ in size, $1 \mathrm{~mm}$ thick) were taken, frozen in liquid nitrogen, and stored at $-80{ }^{\circ} \mathrm{C}$ until analysis of pigments, and enzymatic and non-enzymatic antioxidants.

Measurements of absorptance, PFD, temperature, AND CHLOROPHYLL FLUORESCENCE. Reflectance and transmittance of leaves or fruit peel were measured with an LI-1800 spectroradiometer and the 1800-12S integrating sphere attachment (LI-COR Inc., Lincoln, Neb.). For each leaf, both a reference scan and a sample scan of reflectance or transmittance were made from 400 to $700 \mathrm{~nm}$ at a $1-\mathrm{nm}$ interval. The sample scan was divided by its corresponding reference scan, and integrated over the wavelength range to obtain the average reflectance or transmittance. Leaf absorptance was calculated as 1 - reflectance - transmittance. For fruit, a piece of peel (1 to $1.5 \mathrm{~mm}$ thick) was cut from the sunexposed side of the fruit with a razor blade, and only reflectance was measured. The absorptance of the fruit peel was calculated as 1 - reflectance.

Incident PFD was measured with a recently calibrated LI190SA quantum sensor. Fruit peel temperature was monitored with a thermalcouple.

Chlorophyll fluorescence was measured with a pulse-modulated fluorometer FMS2 (Hansatech, Norfolk, U.K.). For leaves, the fiber optic of the FMS2 was positioned using the PFD/temperature leaf clip at a $60^{\circ}$ angle from the upper surface of the leaf. For fruit, a custom-made device was used to hold the fruit and keep the fiber optic of the FMS2 at about $60^{\circ}$ angle relative to the fruit surface. Maximum fluorescence $\left(F_{m}\right)$ and minimum fluorescence $\left(F_{o}\right)$ of dark-adapted fruit or leaves were measured at predawn. For all the other measurements, steady-state fluorescence $\left(F_{s}\right)$ was monitored to ensure it was stable before a reading was taken.
Maximum fluorescence $\left(F_{m}{ }^{\prime}\right)$ under natural light exposure was obtained by imposing a $1 \mathrm{~s}$ saturating flash of approximately 6,000 $\mu \mathrm{mol} \cdot \mathrm{m}^{-2} \cdot \mathrm{s}^{-1} \mathrm{PFD}$ at leaf or fruit surface in order to reduce all the PSII centers. To determine the minimum fluorescence $\left(F_{o}{ }^{\prime}\right)$ under natural light exposure, a black cloth was used to cover the leaf or fruit while a far-red light was switched on to oxidize PSII rapidly by drawing electrons from PSII to PSI.

The maximum PSII efficiency of dark-adapted fruit or leaves was calculated as: $F_{\mathrm{v}} / F_{\mathrm{m}}=\left(F_{\mathrm{m}}-F_{\mathrm{o}}\right) / F_{\mathrm{m}}$ (van Kooten and Snel, 1990). Because it is almost impossible to keep the distance and the angle between the end of the fiber optic of FMS2 and the fruit surface exactly the same between measurements using one FMS2, non-photochemical quenching, $N P Q=F_{\mathrm{m}} / F_{\mathrm{m}}{ }^{\prime}-1$ (Stern-Volmer quenching, Bilger and Björkman, 1990) can not be calculated. Instead, the efficiency of excitation transfer to PSII centers under natural light exposure, $F_{\mathrm{v}}{ }^{\prime} / F_{\mathrm{m}}{ }^{\prime}=\left(F_{\mathrm{m}}{ }^{\prime}-F_{\mathrm{o}}{ }^{\prime}\right) / F_{\mathrm{m}}{ }^{\prime}$ was used to indicate thermal dissipation. The photochemical quenching coefficient, qP, was calculated as $\left(F_{\mathrm{m}}{ }^{\prime}-F_{\mathrm{s}}\right) /\left(F_{\mathrm{m}}{ }^{\prime}-F_{\mathrm{o}}{ }^{\prime}\right)$. PSII operating efficiency was $\Phi_{\text {PSII }}=\left(F_{\mathrm{m}}{ }^{\prime}-F_{\mathrm{s}}\right) / F_{\mathrm{m}}{ }^{\prime}$ (Genty et al., 1989). The rate of photochemistry and thermal dissipation was calculated as PFD $\times$ absorptance $\times \Phi_{\mathrm{PSII}}$ and PFD $\times$ absorptance $\times\left(F_{\mathrm{v}} / F_{\mathrm{m}}-F_{\mathrm{v}}{ }^{\prime} / F_{\mathrm{m}}{ }^{\prime}\right)$, respectively (Demmig-Adams et al., 1996).

ANALYSIS OF PIGMENTS. Chlorophyll and xanthophyll pigments were extracted from one leaf disc $\left(1 \mathrm{~cm}^{2}\right)$ or two fruit peel discs (total of $2 \mathrm{~cm}^{2}$ ) and analyzed by using an HPLC as described previously (Cheng, 2003).

EXTRACTION AND ASSAY OF ANTIOXIDANT ENZYMES. Antioxidant enzymes were extracted according to Grace and Logan (1996). Briefly, two leaf or fruit peel discs (total of $2 \mathrm{~cm}^{2}$ ) were ground with a pre-cooled mortar and pestle in $3 \mathrm{~mL}$ ice-cold extraction

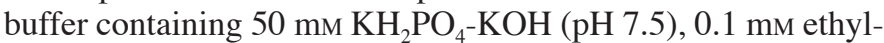
enediaminetetraacetic acid (EDTA), $0.3 \%$ (w/v) Triton X-100, and $4 \%$ (w/v) insoluble polyvinylpolypyrrolidone (PVPP). The extract was kept on ice for $10 \mathrm{~min}$, and then centrifuged at $13,000 \mathrm{~g}_{\mathrm{n}}$ for $10 \mathrm{~min}$ in a microcentrifuge at $2{ }^{\circ} \mathrm{C}$. The supernatant was used immediately for measuring the following antioxidant enzymes.

SOD activity was assayed at $550 \mathrm{~nm}$ by using the cytochrome c method (McCord and Fridovich, 1969). One unit SOD activity is the amount required to produce a $50 \%$ inhibition of cytochrome c reduction.

APX activity was measured by monitoring the decrease in absorbance at $290 \mathrm{~nm}$ (extinction coefficient of $2.8 \mathrm{~mm}^{-1} \cdot \mathrm{cm}^{-1}$ ) (Nakano and Asada, 1981). The assay mixture (1mL) contained 50 mм Hepes-KOH (pH7.6), 0.1 mm EDTA, $0.2 \mathrm{~mm} \mathrm{H}_{2} \mathrm{O}_{2}, 0.5$ $\mathrm{mm}$ AsA and enzyme extract. The reaction was initiated by adding $\mathrm{H}_{2} \mathrm{O}_{2}$.

CAT activity was determined at $240 \mathrm{~nm}$ (extinction coefficient

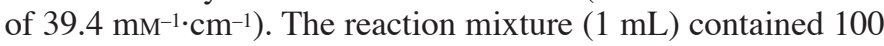
mM potassium phosphate buffer ( $\mathrm{pH} 7.0), 10 \mu \mathrm{L} 10 \%$ (w/v) $\mathrm{H}_{2} \mathrm{O}_{2}$. The reaction was initiated by adding $\mathrm{H}_{2} \mathrm{O}_{2}$ (Rao et al., 1996).

MDAR activity was assayed at $340 \mathrm{~nm}$ (extinction coefficient of $6.2 \mathrm{~mm}^{-1} \cdot \mathrm{cm}^{-1}$ ) in $1 \mathrm{~mL}$ reaction mixture containing $50 \mathrm{~mm}$ Hepes-KOH (pH7.6), 0.1 mm NADH, 0.25 mm AsA, 0.25 units AsA oxidase (EC 1.10.3.3). The reaction was initiated by adding AsA oxidase (Miyake and Asada, 1992).

DHAR activity was measured at $265 \mathrm{~nm}$ (extinction coefficient of $\left.14 \mathrm{~mm}^{-1} \cdot \mathrm{cm}^{-1}\right)$ in $1 \mathrm{~mL}$ assay solution containing 100 mм Hepes-KOH (pH7.0), 1 mм EDTA, 2.5 mм GSH, $0.2 \mathrm{~mm}$ dehydroascorbate (DAsA). The reaction was initiated by adding DAsA (Dalton et al., 1986).

GR activity was monitored at $340 \mathrm{~nm}$ (extinction coefficient of $6.2 \mathrm{~mm}^{-1} \cdot \mathrm{cm}^{-1}$ ) in $1 \mathrm{~mL}$ reaction mixture containing $100 \mathrm{~mm}$ Tris- 
$\mathrm{HCl}$ (pH 8.0), 1 mм EDTA, 1mm oxidized glutathione (GSSG), $0.2 \mathrm{~mm}$ NADPH. The reaction was initiated by adding NADPH (Grace and Logan, 1996).

EXTRACTION AND ANALYSIS OF ANTIOXIDANT METABOLITES. Two discs (total of $2 \mathrm{~cm}^{2}$ ) were ground in $1.5 \mathrm{~mL}$ ice-cold $7 \%(\mathrm{w} / \mathrm{v})$ sulfosalicylic acid. GSH and GSSG were measured according to Griffith (1980).

AsA and DAsA were measured according to Logan et al. (1998) with minor modifications. Briefly, leaf or fruit peel discs were ground in $1.5 \mathrm{~mL}$ ice-cold $6 \%(\mathrm{v} / \mathrm{v}) \mathrm{HClO}_{4}$. The extract was centrifuged at $10,000 \mathrm{~g}$ for $10 \mathrm{~min}$ at $2^{\circ} \mathrm{C}$ and then the supernatant was used immediately for the measurements. One hundred $\mu \mathrm{L}$ of extract was neutralized with $30 \mu \mathrm{L} 1.5 \mathrm{M} \mathrm{Na}_{2} \mathrm{CO}_{3}$ to raise the $\mathrm{pH}$ to $1 \sim 2$. AsA was assayed spectrophotometrically at $265 \mathrm{~nm}$ in $100 \mathrm{mM}$ potassium phosphate buffer (pH5.6), before and after 15 min incubation with 5 units AsA oxidase. For total ascorbate, $100 \mu \mathrm{L}$ of extract was neutralized with $30 \mu \mathrm{L} 1.82 \mathrm{M} \mathrm{Na}_{2} \mathrm{CO}_{3}$ to raise the $\mathrm{pH}$ to $6 \sim 7$ and incubated for $30 \mathrm{~min}$ at room temperature with equal volume $(130 \mu \mathrm{L})$ of $20 \mathrm{~mm}$ GSH in $100 \mathrm{mM}$ Tricine$\mathrm{KOH}$ (pH8.5). Total ascorbate was assayed as above. DAsA was calculated as the difference between total ascorbate and AsA.

\section{Results}

Diurnal Changes of PFD and Temperature. Incident PFD increased in the morning, reached the highest at noon, and then decreased in the afternoon (Fig. 1A). The absorbed PFD in both fruit peel and leaves showed a similar pattern as incident PFD with slightly lower values in fruit peel than in leaves at any given incident PFD.
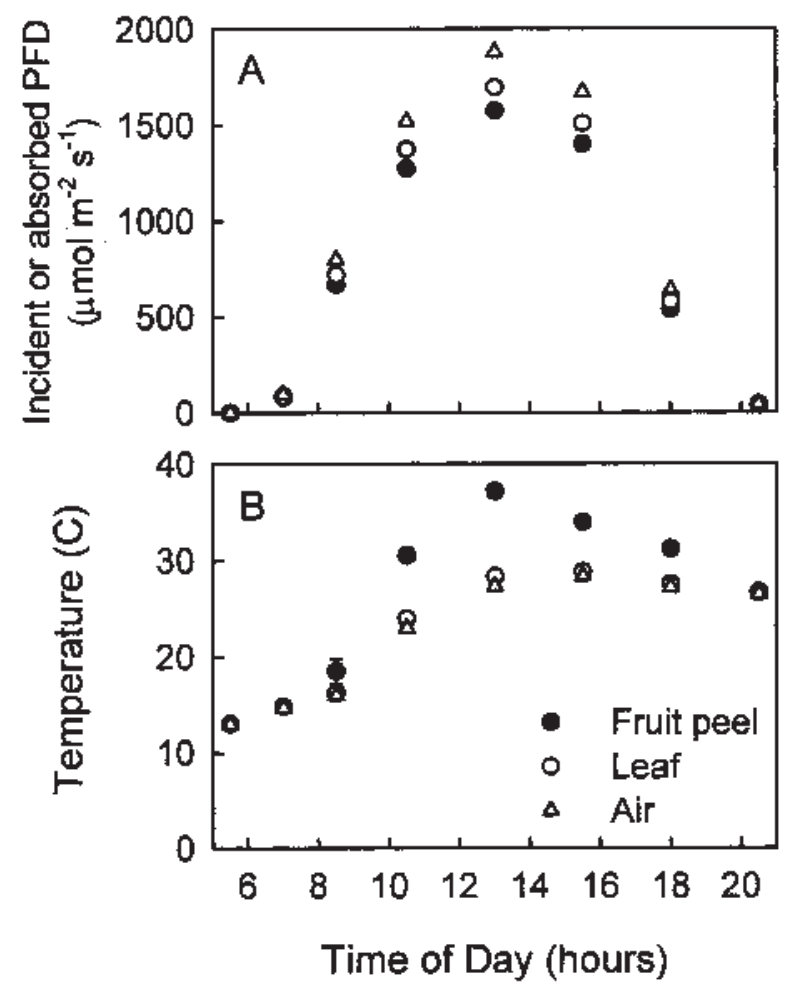

Fig. 1. Diurnal changes of incident and absorbed PFDs (A) and air, leaf and fruit peel temperatures (B) on August 10, 2002. Open triangles represent incident PFD or air temperature; solid circles are absorbed PFD or temperature of fruit peel; open circles are absorbed PFD or temperature of leaves. Eastern Standard Time is used to indicate time of day. Because of the use of daylight saving time, solar noon is at 13:00 $\mathrm{HR}$ instead of 12:00 HR.
Air temperature increased with rising incident PFD in the morning (Fig. 1B). It reached a maximum in the early afternoon, and then declined slightly for the rest of the day. Leaf temperature was similar to air temperature with slightly higher values during midday, but fruit peel temperature was much higher than air temperature for most of the day (Fig. 1B). Fruit peel temperature increased as PFD increased in the morning, reached a maximum at noon, and then declined in the afternoon.

Diurnal PATterns OF CHLOROPHYLl FLUORESCENCE. As PFD increased in the morning, efficiency of excitation transfer $\left(F_{\mathrm{v}}{ }^{\prime} / F_{\mathrm{m}}{ }^{\prime}\right)$, photochemical quenching (qP), and PSII operating efficiency $\left(\Phi_{\mathrm{PSII}}\right)$ of both fruit peel and leaves decreased (Fig. 2). They reached the lowest when PFD was the highest around noon, and then increased as PFD decreased in the afternoon. Compared with leaves, fruit peel had much lower $F_{\mathrm{v}}{ }^{\prime} / F_{\mathrm{m}}{ }^{\prime}, \mathrm{qP}$, and $\Phi_{\text {PSII }}$ at any given PFD throughout the day, and maintained the lowest level for a longer period of time during midday. The predawn value of $F_{\mathrm{v}} / F_{\mathrm{m}}$ was 0.75 for fruit peel and 0.84 for leaves.

The estimated rate of photochemistry and rate of thermal dissipation of both fruit and leaves followed the pattern of incident
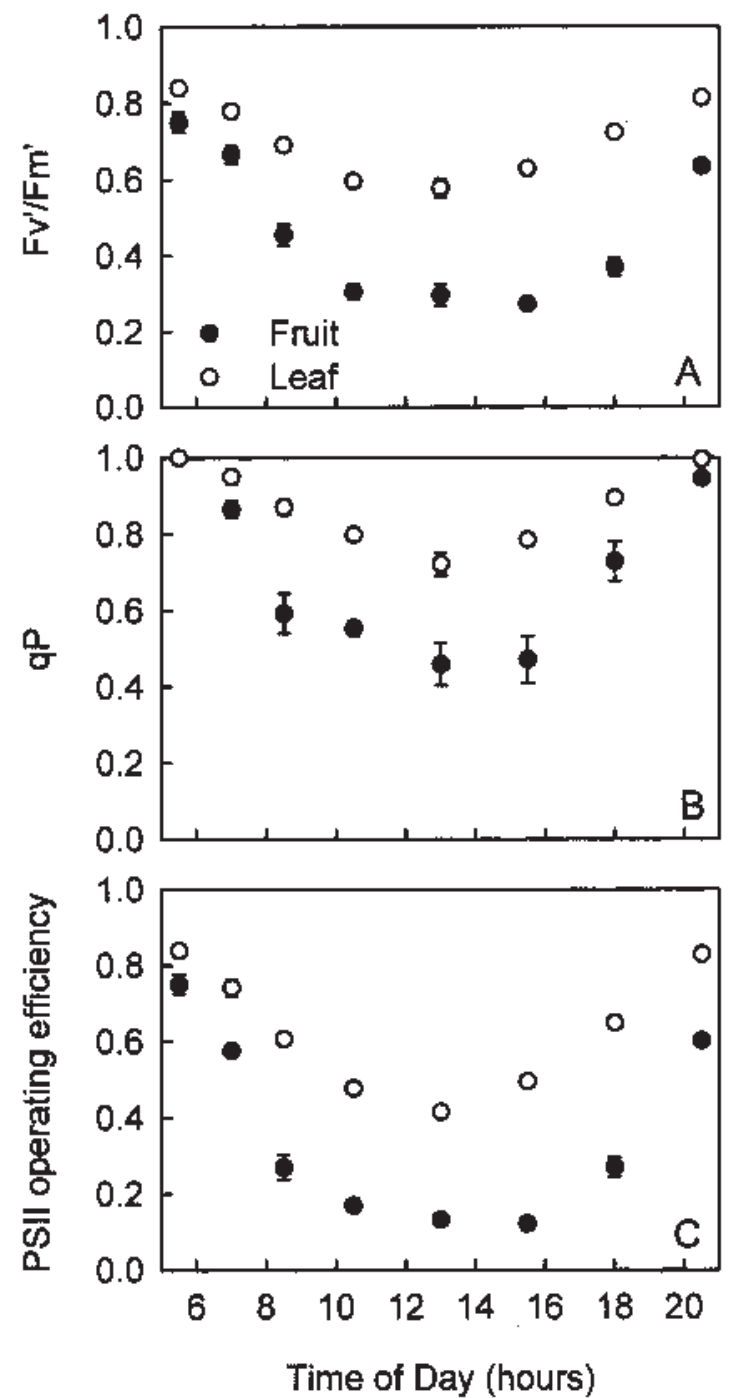

Fig. 2. Diurnal patterns of efficiency of excitation transfer, $F_{\mathrm{v}}{ }^{\prime} / F_{\mathrm{m}}{ }^{\prime}(\mathbf{A})$, photochemical quenching, $\mathrm{qP}(\mathbf{B})$, and PSII operating efficiency $(\mathbf{C})$ of fruit peel and leaves of Liberty/M.9 apple trees in the field. Solid circles represent fruit peel whereas open circles are leaves. Each point is the mean of four replications with standard error. 

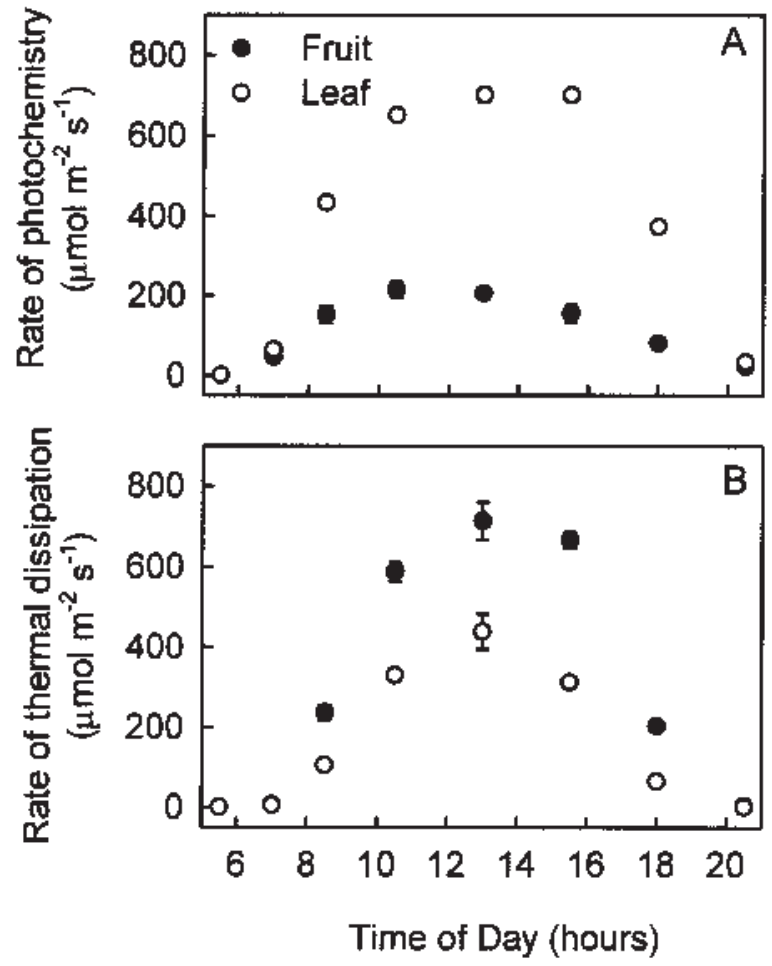

Fig. 3. Diurnal changes of rate of photochemistry (A) and rate of thermal dissipation (B) of fruit peel and leaves of Liberty/M.9 apple trees in the field. Solid circles represent fruit peel whereas open circles are leaves. Each point is the mean of four replications with standard error.

PFD (Fig. 3). However, fruit peel had a much lower rate of photochemistry (Fig. 3A), but a higher rate of thermal dissipation than leaves for most part of the day (Fig. 3B).

Diurnal Changes of Xanthophyll CyCle CONVERSion. As PFD increased in the morning, violaxanthin (V), expressed on a chlorophyll basis, in both fruit peel and leaves decreased (Fig. 4A). They reached the lowest level around noon, and then increased in the afternoon as PFD decreased. Compared with leaves, fruit peel had much higher $\mathrm{V}$ content at predawn but much lower $\mathrm{V}$ content at midday. Correspondingly, zeaxanthin (Z) expressed on a chlorophyll basis in both fruit peel and leaves increased as

Fig. 4. Diurnal patterns of violaxanthin (V) expressed on the basis of chlorophyll (A) or xanthophyll cycle pool $(\mathbf{C})$, and zeaxanthin $(Z)$ on the basis of chlorophyll (B) or xanthophyll cycle pool (D) in fruit peel and leaves of Liberty/M.9 apple trees in the field. Solid circles represent fruit pee whereas open circles are leaves. Each point is the mean of four replications with standard error. On a chlorophyll basis, the xanthophyll cycle pool size is $329.19 \pm 9.28 \mathrm{mmol} \cdot \mathrm{mol}^{-1}$ for fruit peel and $105.04 \pm 2.45 \mathrm{mmol} \cdot \mathrm{mol}^{-1}$ for leaves; On an area basis, the xanthophyll cycle pool size is 13.02 $\pm 0.40 \mathrm{umol} \cdot \mathrm{m}^{-2}$ for fruit peel and 52.44 $\pm 0.56 \mu \mathrm{mol} \cdot \mathrm{m}^{-2}$ for leaves.
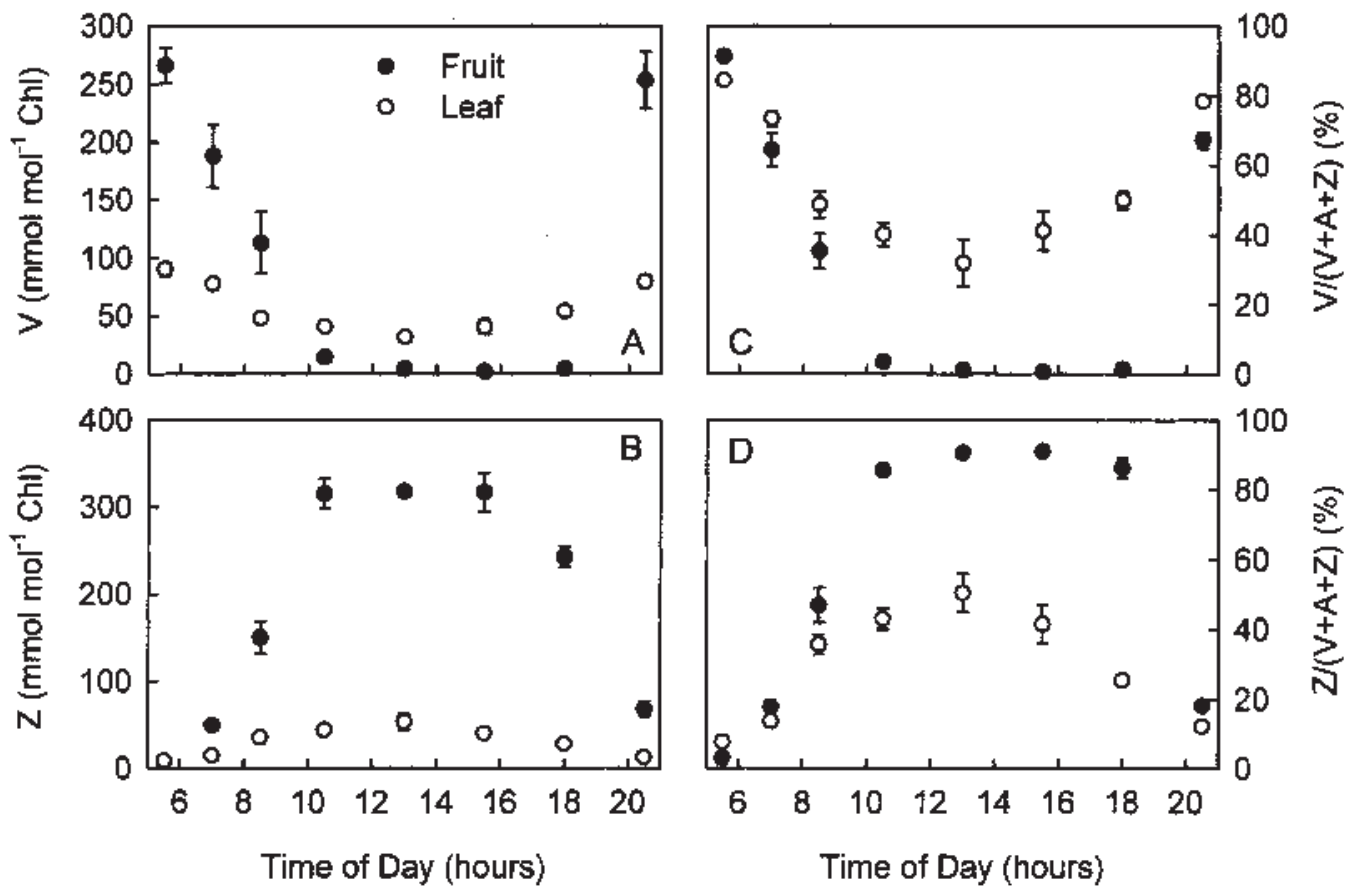

PFD increased in the morning, reached the highest around noon, and then decreased with falling PFD (Fig. 4B). Fruit peel had a much higher level of $\mathrm{Z}$ than leaves at any given $\mathrm{PFD}$ throughout the day and maintained the highest level for a longer period of time during midday.

When expressed as a percentage of the xanthophyll cycle pool, $\mathrm{V}$ in both fruit peel and leaves showed a pattern opposite to that of incident PFD (Fig. 4C), but V in fruit peel declined to almost $0 \%$ during midday compared with $32 \%$ in leaves. $\mathrm{Z}$ in leaves followed the same pattern of incident PFD (Fig. 4D) with the highest level reaching 53\% at noon. Compared with leaves, fruit peel had a higher level of $\mathrm{Z}$ during midday, which accounted for more than $90 \%$ of the xanthophyll cycle pool.

Throughout the day, $F_{\mathrm{v}}{ }^{\prime} / F_{\mathrm{m}}{ }^{\prime}$ showed a negative, linear relationship with $Z$ expressed on a chlorophyll basis, for fruit or leaves, but with different slopes (Fig. $5 \mathrm{~A}$ ); $F_{\mathrm{v}}{ }^{\prime} / F_{\mathrm{m}}{ }^{\prime}$ was negatively correlated with $\mathrm{Z}$ expressed as a percentage of xanthophyll cycle pool for fruit or leaves with similar slopes (Fig. 5B).

DiURnal PaTterns OF ANTIOXIDANT ENZYME aCTIVITIES. SOD activity did not change significantly throughout the day in leaves or fruit peel and there was no significant difference between leaves and fruit peel(Fig. 6A). APX activity in leaves remained unchanged whereas APX activity in fruit peel increased rapidly as PFD increased in the morning, reached the highest level at noon, and then decreased with falling PFD in the afternoon (Fig. 6B). CAT activity in leaves decreased as PFD increased in the morning, reached the lowest level at noon, and then increased with decreasing PFD in the afternoon (Fig. 6C). Fruit peel had a much lower CAT activity than leaves, but showed a similar diurnal pattern as in leaves.

MDAR, DHAR, and GR activities in fruit peel all increased in the morning as PFD increased, reached the highest levels at noon, and then declined as PFD decreased in the afternoon (Fig. 6D-F). In contrast, both MDAR and DHAR activities in leaves were higher in the afternoon than in the morning whereas GR did not change throughout the day.

DiURnal CHANGES OF ANTIOXIDANT METABolites. The total ascorbate pool in leaves did not change significantly, but the reduced ascorbate tended to increase throughout the day (Fig. 7A 

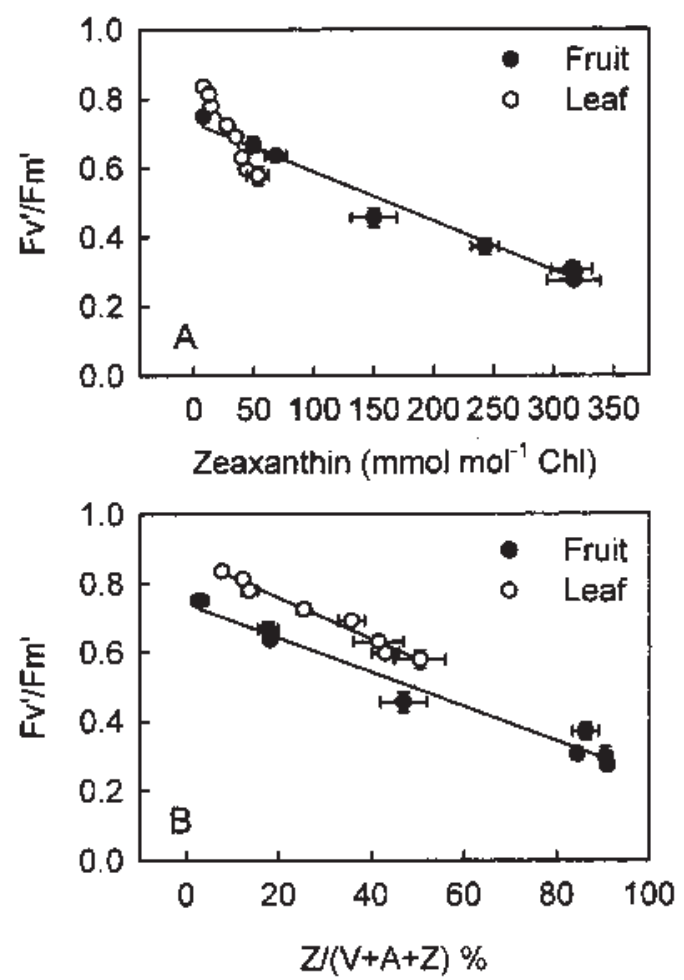

and B). The ratio of reduced ascorbate to oxidized ascorbate of leaves increased in the morning, reached a maximum in the early afternoon, and then decreased for the rest of the day (Fig. 7C). The total ascorbate, the reduced ascorbate, and the ratio of reduced ascorbate to oxidized ascorbate were much lower in fruit peel than in leaves. They all showed a similar diurnal pattern with a maximum showing up in the early afternoon (Fig. 7A-C).

Total glutathione, reduced glutathione, and the ratio of reduced to oxidized glutathione in both leaves and fruit peel increased in the morning, reached a maximum in the early afternoon, and then decreased for the rest of the day (Fig. 7D-F).

\section{Discussion}

Our data (Fig. 2C and 3A) clearly showed that the proportion

Fig. 6. Diurnal course of superoxide dismutase, SOD (A), ascorbate peroxidase, APX (B), catalase, CAT (C), monodehydroascorbate reductase, MDAR (D), dehydroascorbate reductase, DHAR (E), and glutathione reductase, GR $(\mathbf{F})$ in fruit peel and leaves of Liberty/M.9 apple trees in the field. Solid circles represent fruit peel whereas open circles are leaves. Each point is the mean of four replications with standard error.
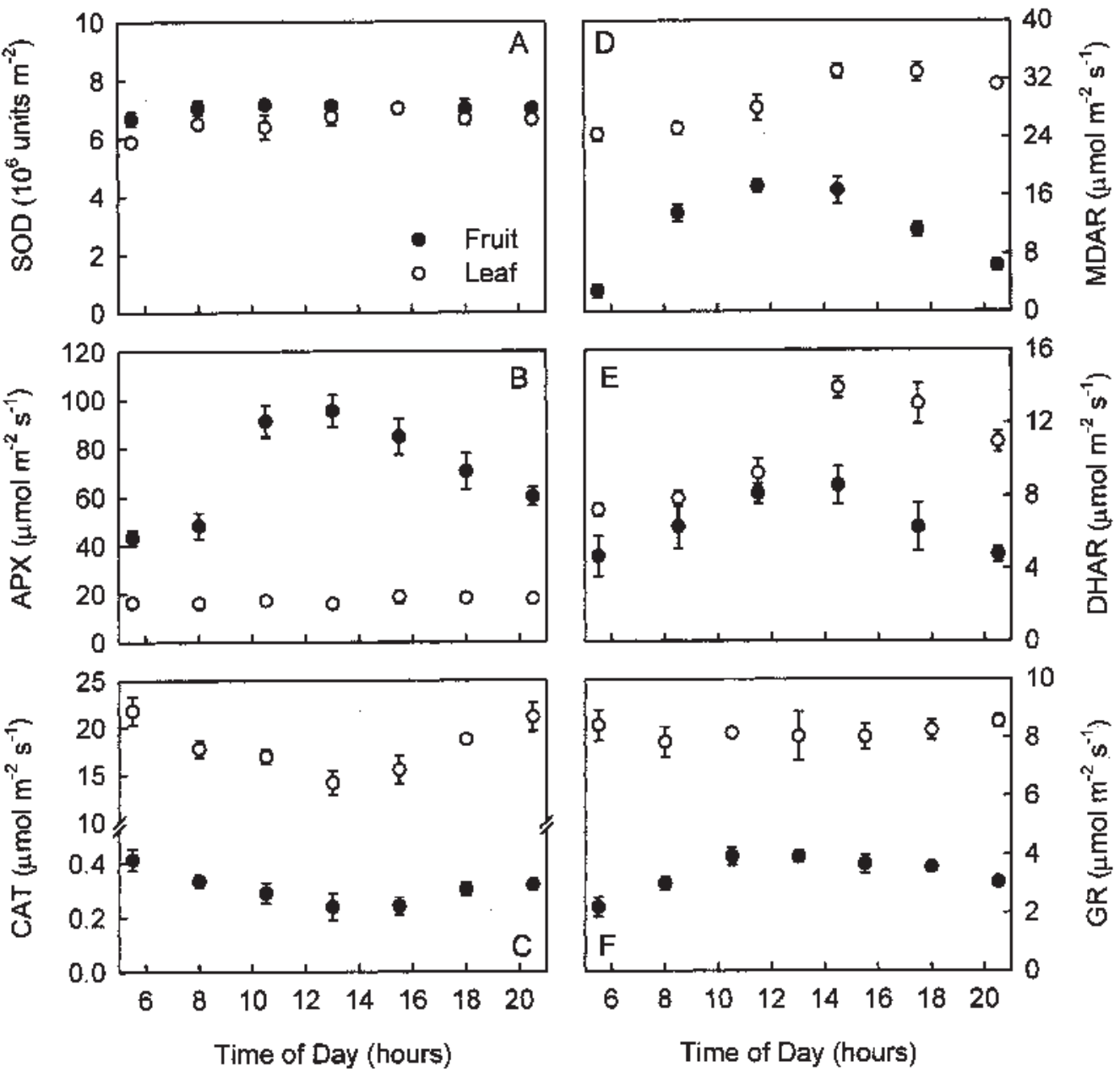

of absorbed PFD used in photochemical processes and the rate of photochemistry of apple fruit peel was much lower than that of leaves at any give PFD. As a result, the excess absorbed PFD in fruit peel was much greater at the same incident PFD than in leaves. Although we did not directly measure non-photochemical quenching because of the limitation of the attached fruit itself, both efficiency of excitation transfer, $F_{\mathrm{v}}{ }^{\prime} / F_{\mathrm{m}}{ }^{\prime}$ (Fig. 2A) and the estimated rate of thermal dissipation (Fig. 3B) indicate that thermal dissipation of excess excitation energy was up-regulated to cope with the excess absorbed PFD.

Thermal dissipation of excitation energy is dependent on the pool size and the conversion of the xanthophyll cycle (DemmigAdams and Adams, 1996; Niyogi et al., 1998). The negative relationship of $F_{\mathrm{v}}{ }^{\prime} / F_{\mathrm{m}}{ }^{\prime}$ with $\mathrm{Z}$ content, expressed on a leaf chlorophyll basis or as a percentage of the xanthophyll cycle pool (Fig. 5), indicates that thermal dissipation is closely related to the operation of xanthophyll cycle throughout the day. Compared with leaves, fruit peel had a larger xanthophyll cycle pool on a chlorophyll basis (Fig. 4A and B). Over a diurnal course, the conversion of $\mathrm{V}$ to $\mathrm{Z}$ in both fruit and leaves showed a pattern similar to that to zeaxanthin expressed on the basis of chlorophyll (A) or xanthophyll cycle pool (B) throughout the day. Solid circles represent fruit peel whereas open error. Regression equations $(\mathbf{A})$ : for fruit peel $\mathrm{Y}=0.731-0.00143 \mathrm{X}\left(r^{2}=0.976\right.$ $P<0.0001)$; for leaves $\mathrm{Y}=0.88-0.00594 \mathrm{X}\left(r^{2}=0.974 ; P<0.0001\right)$; $(\mathbf{B})$ for fruit peel $\mathrm{Y}=0.739-0.00495 \mathrm{X}\left(r^{2}=0.969 ; P<0.0001\right)$; for leaves $\mathrm{Y}=0.878$ $-0.00603 X\left(r^{2}=0.975 ; P<0.0001\right)$ 


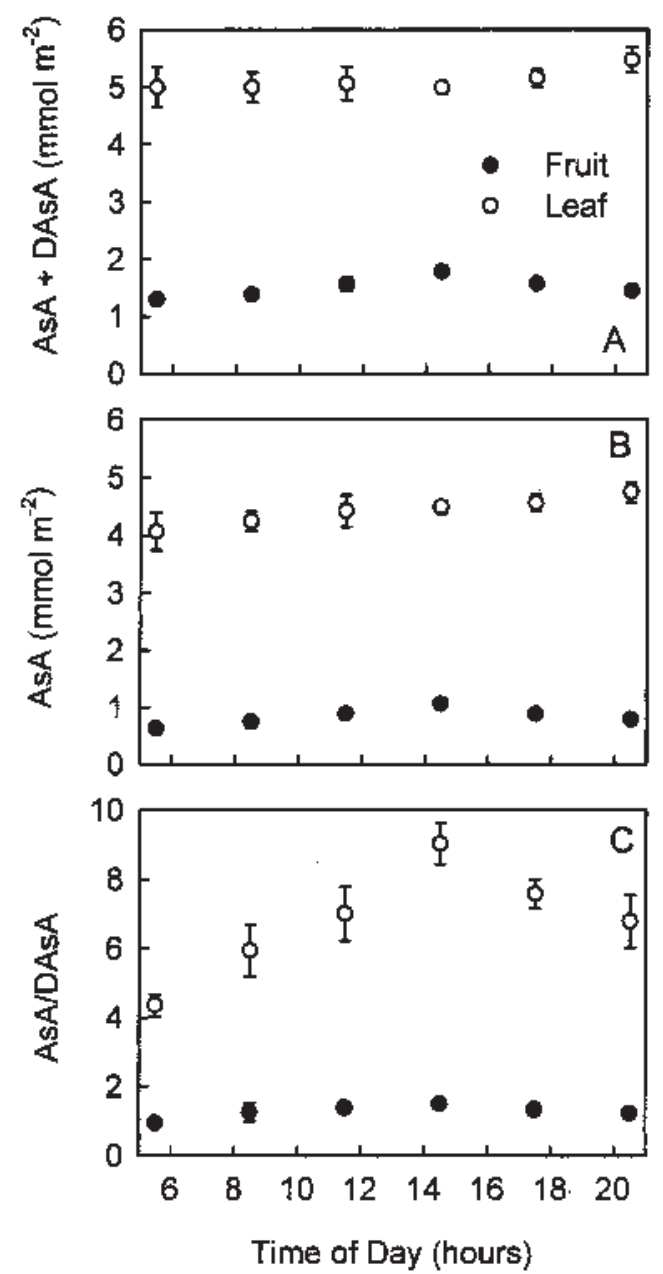

Fig. 7. Diurnal changes of ascorbate pool, AsA + DAsA (A), reduced ascorbate, AsA (B), the ratio of reduced ascorbate to oxidized ascorbate (DAsA), AsA/ DAsA (C), total glutathione pool, GSH + GSSG (D), reduced glutathione, $\mathrm{GSH}(\mathbf{E})$, and the ratio of reduced glutathione to oxidized glutathione (GSSG), GSH/GSSG (F) in fruit peel and leaves of Liberty/M.9 apple trees in the field. Solid circles represent fruit peel whereas open circles are leaves. Each point is the mean of four replications with standard error.

of incident PFD (Fig. 4D). This is consistent with that observed in leaves of other species (Adams and Demmig-Adams, 1992). However, fruit peel has a much higher degree of de-epoxidation of the xanthophyll cycle for most of the day. At noon, over $90 \%$ of the xanthophyll cycle pool was present in $\mathrm{Z}$ with very little in $\mathrm{V}$ in fruit peel compared with $53 \%$ in $\mathrm{Z}$ and $32 \%$ in $\mathrm{V}$ in leaves (Fig. 4C and D). This indicates that xanthophyll cycle in fruit peel operates at its full capacity for several hours during midday to dissipate the excess absorbed PFD while only a proportion of the xanthophyll cycle capacity of the leaves is used. This corresponds to the difference in the amount of excess absorbed PFD between fruit and leaves at the same incident PFD during midday. Zeaxanthin is also able to quench singlet oxygen (Baroli et al., 2003; Havaux and Niyogi, 1999). Compared with leaves, the larger xanthophyll cycle pool size in fruit peel may also indicate an increased capacity for quenching ${ }^{1} \mathrm{O}_{2}$ as production of ${ }^{1} \mathrm{O}_{2}$ may be higher due to a higher degree of closure of PSII under high PFD (Fig. 2B). The diurnal change of $\mathrm{Z}$ in the fruit peel is also consistent with the changing needs for quenching singlet oxygen at different excess PFD levels during the day.

Part of the linear electron flow from PSII to PSI is due to direct photoreduction of oxygen and the subsequent detoxification of the reduced oxygen species. Because this process uses electrons derived from water to reduce oxygen to water at the end (water-water cycle, Asada, 1999), it does not have net oxygen exchange. Unless stable isotopes are simultaneously measured, it is difficult to assess the rate of photoreduction of oxygen. We did not directly determine the rate of photoreduction of oxygen in fruit peel or leaves. However, the similarity in diurnal patterns between activities of antioxidant enzymes (APX, MDAR, DHAR, and GR) in fruit peel and the incident PFD (Fig. 6B, D, and E, and F) strongly suggests that the photoreduction of oxygen in fruit peel corresponds to the diurnal change of PFD. In contrast, both APX and GR in leaves did not change significantly although the activities of MDAR and DHAR were higher in the afternoon than in the morning (Fig. 6D and E). The difference between fruit peel and leaves may be related to the fact that fruit peel has more excess absorbed PFD due to its lower capacity for photosynthesis than leaves at the same PFD, and that the xanthophyll cycle-dependent thermal dissipation operates at full capacity in fruit peel to dissipate excess excitation energy at high PFDs during midday. Consequently, there is a greater need to dissipate absorbed PFD via photoreduction of oxygen for most part of the day and to regulate the down-stream antioxidant system accordingly to scavenge the reactive oxygen species generated.

Our data showed that SOD activity in both apple peel and leaves were relatively high compared with other species (Logan et al., 1998, 1999) and remained unchanged during the day (Fig. 6A). This suggests that SOD activity in apple fruit peel and leaves are high enough to cope with the changes in superoxide production at different PFDs during the day. SOD activity in sun leaves of cork oak was also reported to be similar between predawn and midday (Faria et al., 1996).

APX activity measured in this experiment is its total activity. There are at least four isoforms of APX that contribute to the total activity: the stromal APX (sAPX) and thylakoid membrane-bound APX (tAPX) in chloroplasts, the microbody (gloxysome and peroxisome) membrane-bound APX (mAPX), and the cytosol APX (cAPX) (Shigeoka et al., 2002). Diurnal regulation of APX in leaves depends on individual isoforms and also varies among species. In response to high light stress, the steady state transcript level and activity of cAPX in spinach leaves increase remarkably whereas the transcript levels and activities of chloroplastic APX (sAPX and tAPX) and microbody-bound APX isoenzymes remain unchanged (Yoshimura et al., 2000). However, no diurnal change was found in the transcript level and activity of cAPX in Nicotiana plumbaginifolia (Willekens et al., 1994). The total activity of APX in apple leaves remained 
constant during the day (Fig. 6B). This is similar to that observed in leaves of cork oak (Faria et al., 1996) and beech (Fagus sylvatica) (Peltzer and Polle, 2001). However, APX activity of apple fruit peel exhibited a pronounced diurnal change similar to that of incident PFD (Fig. 6B). The exact mechanism of APX regulation in apple fruit peel versus leaves is unclear. Both redox status of the electron transport through plastoquinone and cellular $\mathrm{H}_{2} \mathrm{O}_{2}$ concentration are involved in regulating cAPX activity in response to high light stress (Karpinska et al., 2000; Karpinski et al., 1997; 1999; Morita et al., 1999). As shown in Fig. 2B, the photochemical quenching coefficient (qP) was much lower in fruit peel than in leaves at any given PFD. One possibility is that the redox change of the electron transport chain in fruit peel is large enough to up-regulate the expression of cAPX genes while that in leaves is not, assuming both fruit peel and leaves have the same isoforms of APX. It is also possible that the cellular $\mathrm{H}_{2} \mathrm{O}_{2}$ accumulation is higher in fruit peel than in leaves due to higher rate of photoreduction of oxygen and lower CAT activity, which up-regulates APX expression via redox signal transduction (Lee et al., 1999; Morita et al., 1999). In any case, comparing redox status of electron transport, cellular $\mathrm{H}_{2} \mathrm{O}_{2}$ levels, and expression of different isoforms of APX between fruit peel and leaves would help to elucidate the regulatory mechanism.

The activity of CAT in fruit peel was much lower than that in leaves (Fig. 6C). CAT is primarily localized in peroxisomes (Willekens et al., 1995), where it removes the bulk of $\mathrm{H}_{2} \mathrm{O}_{2}$ produced in photorespiration. Compared with leaves, fruit peel has much lower stomatal density and higher internal $\mathrm{CO}_{2}$ concentration due to respiration of the bulk tissue (Blanke and Lenz, 1989). It is expected that photorespiration in fruit peel is very low. This may be why fruit peel has much lower CAT activity than leaves. CAT is sensitive to photoinactivation in vivo and in vitro (Feierabend and Engel, 1986; Willekens et al., 1995). The midday depression of the CAT activity in both apple fruit peel and leaves (Fig. 6C) suggests that photoinactivation of CAT may be occurring at a higher rate under high PFD at midday.

Both MDAR and DHAR in fruit peel showed a diurnal pattern similar to that of APX (Fig. 6D and E). The higher ratio of AsA to DAsA in fruit peel during midday (Fig. 7C) indicates that the regeneration of AsA is increased compared with at predawn and dusk. However, the ratio of AsA to DAsA in fruit peel was much lower than in leaves throughout the day (Fig. 7C). This may be related to the fact that fruit peel has a much smaller ascorbate pool size on a surface area basis than leaves (Fig. 7A) and both the conversion of $\mathrm{V}$ to $\mathrm{Z}$ via $\mathrm{A}$ at full capacity (Fig. 4) and conversion of $\mathrm{H}_{2} \mathrm{O}_{2}$ to water by high APX activity in fruit peel (Fig. 6B) consume a large amount of AsA. As a result, the regeneration of AsA in fruit peel may not be fast enough to keep the ascorbate pool at the same reduction state as in leaves. Under normal circumstances, AsA accounts for most of the total ascorbate pool in plants (Smirnoff and Pallanca, 1996). The decreased ratio of AsA to DAsA in fruit peel indicates that certain level of oxidative damage may have occurred (Gossett et al., 1994; Law et al., 1983). This was also reflected in the lower $F_{\mathrm{v}} / F_{\mathrm{m}}$ value of fruit peel at predawn in comparison with leaves (Fig. 2A) as fruit peel had a similar Z content on a chlorophyll basis and a slightly higher $\mathrm{Z}$ level on xanthophyll cycle pool basis at predawn (Fig. $4 \mathrm{~B}$ and $\mathrm{D})$.

The diurnal pattern of total glutathione pool in both apple fruit peel and leaves (Fig. 7D) is similar to that found in Homogyne alpinum leaves (Wildi and Lütz, 1996) and spruce (Picea abies L.) needles (Schupp and Rennenberg 1988). The glutathione pool size is determined by GSH synthesis, degradation, and translocation. The synthesis of GSH is dependent on the glycine formation in photorespiration (Noctor et al., 1997) whereas its export increases in darkness (Schupp et al., 1992). The increase in GSH level and the ratio of GSH/GSSG in apple fruit peel during the midday (Fig. $7 \mathrm{E}$ and $\mathrm{F}$ ) is consistent with the increased GR activity (Fig. 6F). However, GR activity in leaves remained constant throughout the day, yet the GSH level and the ratio of GSH/GSSG still showed a similar diurnal pattern as in fruit peel. Considering leaves had much higher GR activity than in fruit peel, it is possible that only a proportion of the total GR in leaves is engaged in converting GSSG to GSH in vivo.

In summary, apple fruit peel has more excess absorbed PFD and higher surface temperature than leaves at the same incident PFD for most part of the day. Compared with leaves, sun-exposed fruit peel has a larger xanthophyll cycle pool on a chlorophyll basis, which operates at its full capacity for several hours during the midday. Most antioxidant enzymes in fruit peel show a diurnal pattern similar to that of incident PFD. This strongly suggests that photoreduction of oxygen corresponds to the diurnal change of PFD. Therefore, we conclude that both xanthophyll cycle conversion and the antioxidant system are regulated in response to PFD over a diurnal course to protect fruit from excess absorbed PFD.

\section{Literature Cited}

Adams, III, W.W. and B. Demmig-Adams. 1992. Operation of the xanthophyll cycle in higher plants in response to diurnal changes in incident light. Planta 186:390-398.

Asada, K. 1999. The water-water cycle in chloroplasts: Scavenging of active oxygens and dissipation of excess photons. Annu. Rev. Plant Physiol. Plant Mol. Biol. 50:601-639.

Baroli, I., A.D. Do, T. Yamane, and K.K. Niyogi. 2003. Zeaxanthin accumulation in the absence of a functional xanthophyll cycle protects Chlamydomonas reinhardtii from photooxidative stress. Plant Cell 15:992-1008.

Bilger, W. and O.B. Björkman. 1990. Role of the xanthophyll cycle in photoprotection elucidated by measurements of light-induced absorbance changes, fluorescence and photosynthesis in leaves of Hedera canariensis. Photosyn. Res. 25:173-185.

Blanke, M.M. and D.H. Lenz. 1989. Fruit photosynthesis. Plant Cell Environ. 12:31-46.

Cheng, L. 2003. Xanthophyll cycle pool size and composition in relation to the nitrogen content of apple leaves. J. Expt. Bot. 54:385-393.

Dalton, D.A., S.A. Russell, F.J. Hanus, G.A. Pascoe, and H.J. Evans. 1986. Enzymatic reactions of ascorbate and glutathione that prevent peroxide damage in soybean root nodules. Proc. Natl. Acad. Sci. USA 83:3811-3815.

Demmig-Adams, B. and W.W. Adams, III. 1992. Photoprotection and other responses of plants to high light stress. Annu. Rev. Plant Physiol. Plant Mol. Biol. 43:599-626.

Demmig-Adams, B. and W.W. Adams, III. 1996. Xanthophyll cycle and light stress in nature: Uniform response to excess direct sunlight among higher plant species. Planta 198:460-470.

Demmig-Adams, B., W.W. Adams, III, D.H. Barker, B.A. Logan, D.R. Bowling, and A.S. Verhoeven. 1996. Using chlorophyll fluorescence to assess the fraction of absorbed light allocated to thermal dissipation of excess excitation. Physiol. Plant. 98:253-264.

Demmig-Adams, B., W.W. Adams, III, and S.C. Grace. 1997. Physiology of light tolerance in plants. Hort. Rev. 18:215-246.

Faria, T., J.I. García-Plazaola, A. Abadía, S. Cerasoli, J.S. Pereira, and M.M. Chaves. 1996. Diurnal changes in photoprotective mechanisms in leaves of cork oak (Quercus suber) during summer. Tree Physiol 16:115-123.

Feierabend, J. and S. Engel. 1986. Photoinactivation of catalase in vitro 
and in leaves. Arch. Biochem. Biophys. 251:567-576.

Genty, B., J.M. Briantais, and N.R. Baker. 1989. The relationship between quantum yield of photosynthetic electron transport and quenching of chlorophyll fluorescence. Biochim. Biophys. Acta 990:87-92.

Gilmore, A.M. 1997. Mechanistic aspects of xanthophyll cycle-dependent photoprotection in higher plant chloroplasts and leaves. Physiol. Plant. 99:197-209.

Glenn, D.M.,E. Prado,A. Erez, J. McFerson, and G.J.Puterka. 2002. Reflective, process-Kaolin particle film affects fruit temperature, radiation reflection, and solar injury in apple. J. Amer. Soc. Hort. Sci. 127:188-193.

Grace, S.C. and B.A. Logan. 1996. Acclimation of foliar antioxidant systems to growth irradiance in three broad-leaved evergreen species. Plant Physiol. 112:1631-1640.

Gossett, D.R., E.P. Millhollon, and M.C. Lucas. 1994. Antioxidant responses to $\mathrm{NaCl}$ stress in salt-tolerant and salt-sensitive cultivars of cotton. Crop Sci. 34:706-714.

Griffith, O.W. 1980. Determination of glutathione and glutathione disulfide using glutathione reductase and 2-vinylpyridine. Anal. Biochem. 106:207-212.

Hager, A. 1969. Lichtbedingte $\mathrm{pH}-$ Erniedrigung in einem Chloroplasten-Kompartiment als Ursache der enzymatischen Violaxanthin-Zeaxanthin-Umwandlung: Beziehung zur Photophosphorylierung. Planta 89:224-243.

Hager, A. and K. Holocher. 1994. Localization of the xanthophyll-cycle enzyme violaxanthin de-epoxidase within the thylakoid lumen and abolition of its mobility by a (light-dependent) $\mathrm{pH}$ decrease. Planta 192:581-589.

Havaux, M. and K.K. Niyogi. 1999. The violaxanthin cycle protects plants from photooxidative damage by more than one mechanism. Proc. Natl. Acad. Sci. USA 96:8762-8767.

Karpinska, B., G. Wingsle, and S. Karpinski. 2000. Antagonistic effects of hydrogen peroxide and glutathione on acclimation to excess excitation energy in Arabidopsis. IUBMB Life 50:21-26.

Karpinski, S., C. Escobar, B. Karpinska, G. Creissen, and P.M. Mullineaux. 1997. Photosynthetic electron transport regulates the expression of cytosolic ascorbate peroxidase genes in Arabidopsis during excess light stress. Plant Cell 9:627-640.

Karpinski, S., H. Reynolds, B. Karpinska, G. Wingsle, G. Creissen, and P.M. Mullineaux. 1999. Systemic signaling and acclimation in response to excess excitation energy in Arabidopsis. Science 284:654-657.

Law, M.Y., S.A. Charles, and B. Halliwell. 1983. Glutathione and ascorbic acid in spinach (Spinacia oleracea) chloroplasts: The effect of hydrogen peroxide and of paraquat. Biochem. J. 210:899-903.

Lee, S.C., B.G. Kang, and S.E. Oh. 1999. Induction of ascorbate peroxidase by ethylene and hydrogen peroxide during growth of cultured soybean cells. Molecules and Cells 9:166-171.

Logan, B.A., B. Demmig-Adams, T.N. Rosenstiel, and W.W. Adams, III. 1999. Effects of nitrogen limitation on foliar antioxidants in relationship to other metabolic characteristics. Planta 209:213-220.

Logan, B.A., S.C. Grace, W.W. Adams, III, and B. Demmig-Adams. 1998. Seasonal differences in xanthophyll cycle characteristics and antioxidants in Mahonia repens growing in different light environments. Oecologia 116:9-17.

McCord, J.M. and I. Fridovich. 1969. Superoxide dismutase. An enzymic function for erythrocuprein (hemocuprein). J. Biol. Chem. 244: 6049-6055.

Miyake, C. and K. Asada. 1992. Thylakoid-bound ascorbate peroxidase in spinach chloroplasts and photoreduction of its primary oxidation product monodehydroascorbate radicals in thylakoids. Plant Cell Physiol. 33:541-553.

Morita, S., H. Kaminaka, T. Masumura, and K. Tanaka. 1999. Induction of rice cytosolic ascorbate peroxidase mRNA by oxidative stress; the involvement of hydrogen peroxide in oxidative signaling. Plant Cell Physiol. 40:417-422.

Müller, P., X.P.Li, and K.K. Niyogi. 2001. Non-photochemical quenching. A response to excess light energy. Plant Physiol. 125:1558-1566.

Nakano, Y. and K. Asada. 1981. Hydrogen peroxide is scavenged by ascorbate-specific peroxidase in spinach chloroplasts. Plant Cell Physiol. 22:867-880.

Niyogi, K.K., A.R. Grossman, and O. Björkman. 1998. Arabidopsis mutants define a central role of the xanthophyll cycle in the regulation of photosynthetic energy conversion. Plant Cell 10:1121-1134.

Noctor, G. and C.H. Foyer. 1998. Ascorbate and glutathione: keep active oxygen under control. Annu. Rev. Plant Physiol. Plant Mol. Biol. 49:249-279.

Noctor, G., A.C.M. Arisi, L. Jouanin, M.H. Valadier, Y. Roux, and C.H. Foyer. 1997. Light-dependent modulation of foliar glutathione synthesis and associated amino acid metabolism in poplar overexpressing $\gamma$-glutamylcysteine synthase. Planta 202:357-369.

Peltzer, D. and A. Polle. 2001. Diurnal fluctuations of antioxidant systems in leaves of field-grown beech trees (Fagus sylvatica): Responses to light and temperature. Physiol. Plant. 111:158-164.

Rao, M.V., G. Paliyath, and D.P. Ormrod. 1996. Ultraviolet-B- and ozoneinduced biochemical changes in antioxidant enzymes of Arabidopsis thaliana. Plant Physiol. 110:125-136.

Schupp, R. and H. Rennenberg. 1988. Diurnal changes in the glutathione content of spruce needles (Picea abies L.). Plant Sci. 57:113-117.

Schupp, R., T. Schatten, J. Willenbrinkl, and H. Rennenberg. 1992. Long-distance transport of reduced sulphur in spruce (Picea abies L.). J. Expt. Bot. 43:1243-1250.

Shigeoka, S., T. Ishikawa, M. Tamoi, Y. Miyagawa, T. Takeda, Y. Yabuta, and K. Yoshimura. 2002. Regulation and function of ascorbate peroxidase isoenzymes. J. Expt. Bot. 53:1305-1319.

Smirnoff, N. and J.E. Pallanca. 1996. Ascorbate metabolism in relation to oxidative stress. Biochem. Soc. Trans. 24:472-478.

van Kooten, O. and J.F.H. Snel. 1990. The use of chlorophyll fluorescence nomenclature in plant stress physiology. Photosyn. Res. 25: $147-150$

Wildi, B. and C. Lütz. 1996. Antioxidant composition of selected high alpine plant species from different altitudes. Plant Cell Environ. 19: 136-146.

Willekens, H., D. Inzé, M. van Montagu, and W. van Camp. 1995. Catalase in plants. Molecular Breeding 1:207-228.

Willekens, H., W. van Camp, M. van Montagu, D. Inzé, C. Langebartels, and H. Sandermann, Jr. 1994. Ozone, sulfur dioxide, and ultraviolet B have similar effects on mRNA accumulation of antioxidant genes in Nicotiana plumbaginifolia L. Plant Physiol. 106:1007-1014.

Yang, C.W., Y.Z. Chen, C.H. Peng, D. Jun, and G.Z. Lin. 2001. Daily changes in components of xanthophyll cycle and antioxidant systems in leaves of rice at different developing stage. Acta Physiol. Plant. 23: 391-398.

Yoshimura, K., Y. Yabuta, T. Ishikawa, and S. Shigeoka. 2000. Expression of spinach ascorbate peroxidase isoenzymes in responses to oxidative stress. Plant Physiol. 123:223-233. 